\title{
Levels of 25-hydroxyvitamin D in familial longevity: the Leiden Longevity Study
}

\author{
Raymond Noordam MSc, Anton J.M. de Craen PhD, Pardis Pedram MD MSc, Andrea B. Maier MD PhD, \\ Simon P. Mooijaart MD PhD, Johannes van Pelt PhD, Edith J. Feskens PhD, Martinette T. Streppel PhD, \\ P. Eline Slagboom PhD, Rudi G.J. Westendorp MD PhD, Marian Beekman PhD, Diana van Heemst PhD
}

\begin{abstract}
Background: Low levels of $25(\mathrm{OH})$ vitamin D are associated with various age-related diseases and mortality, but causality has not been determined. We investigated vitamin D levels in the offspring of nonagenarians who had at least one nonagenarian sibling; these offspring have a lower prevalence of age-related diseases and a higher propensity to reach old age compared with their partners.
\end{abstract}

Methods: We assessed anthropometric characteristics, 25(OH) vitamin D levels, parathyroid hormone levels, dietary vitamin $\mathrm{D}$ intake and single nucleotide polymorphisms (SNPs) associated with vitamin D levels. We included offspring $(n=1038)$ of nonagenarians who had at least one nonagenarian sibling, and the offsprings' partners ( $n=$ 461; controls) from the Leiden Longevity Study. We included age, sex, body mass index, month during which blood sampling was performed, dietary and supplemental vitamin D intake, and creatinine levels as possible confounding factors.
Results: The offspring had significantly lower levels of vitamin $D(64.3 \mathrm{nmol} / \mathrm{L})$ compared with controls ( $68.4 \mathrm{nmol} / \mathrm{L} ; p=0.002)$, independent of possible confounding factors. There was no difference in the levels of parathyroid hormone between groups. Compared with controls, the offspring had a lower frequency of a genetic variant in the CYP2R1 gene (rs2060793) $(p=$ 0.04). The difference in vitamin $D$ levels between offspring and controls persisted over the 2 most prevalent genotypes of this SNP.

Interpretation: Compared with controls, the offspring of nonagenarians who had at least one nonagenarian sibling had a reduced frequency of a common variant in the CYP2R1 gene, which predisposes people to high vitamin $D$ levels; they also had lower levels of vitamin $D$ that persisted over the 2 most prevalent genotypes. These results cast doubt on the causal nature of previously reported associations between low levels of vitamin D and age-related diseases and mortality.
$\mathrm{V}$ itamin D plays a critical role in bone formation, ${ }^{1}$ immune cell differentiation, and in the inhibition of proliferation and angiogenesis in cancer. ${ }^{2}$ Low serum levels of 25 hydroxyvitamin D3 $(25[\mathrm{OH}]$ vitamin D) are associated with increased mortality, cardiovascular disease, diabetes mellitus, cancer, multiple sclerosis, allergy, asthma, infection, depression, mental illness and musculoskeletal pain. ${ }^{3-6}$ However, because of design limitations, previous studies have not been able to infer causality. ${ }^{7}$ A metaanalysis that included 51 studies and more than 30000 individuals in each treatment group showed no reduction in all-cause or cardiovascular mortality with vitamin D supplementation, ${ }^{8}$ suggesting that low serum levels of vitamin $\mathrm{D}$ are a consequence rather than a cause of disease.

Vitamin D status is routinely assessed by measurement of serum concentration of the prohormone $25(\mathrm{OH})$ vitamin $\mathrm{D}$, which is the most stable and abundant metabolite of vitamin D in circulation. In the current study, we investigated the asso- ciation between serum levels of $25(\mathrm{OH})$ vitamin $\mathrm{D}$ and familial longevity. We assessed vitamin D levels in the offspring of nonagenarian siblings whom we have previously shown to have a lower prevalence of cardiovascular diseases and lower mortality compared to age- and environmentalmatched controls. ${ }^{9}{ }^{10}$ We also assessed whether genetic variation in 3 genes ${ }^{11}$ was associated with $25(\mathrm{OH})$ vitamin D levels among the offspring of nonagenarians who had at least 1 nonagenarian sibling, and their partners.

\section{Methods}

\section{Study design}

The Leiden Longevity Study was designed to identify genetic and phenotypic markers related to familial longevity. A total of 421 families were recruited, consisting of long-lived white siblings, offspring and the offspring's partners. Families were only included if at least 2 long-lived siblings were still alive and met the age criteria $(\geq 89 \mathrm{yr}$
Competing interests: None declared.

This article has been peer reviewed.

Correspondence to: Diana van Heemst, d.van_heemst@lumc.nl

CMAJ 2012. DOI:10.1503 /cmaj.120233 
for men; $\geq 91 \mathrm{yr}$ for women)..$^{10}$ There was no selection based on health conditions or demographic characteristics. Nonagenarian siblings had a $41 \%$ lower mortality risk compared with sporadic nonagenarians. ${ }^{9}$ Because it is difficult to include proper controls for this age group, the nonagenarian's offspring were asked to participate and serve as cases, because they have an increased propensity to reach old age. ${ }^{10}$ The offsprings' partners were asked to participate in the study as environment-matched controls of a similar age because they tended to be similar for many of the environmental factors that might influence vitamin D levels.

The Leiden Longevity Study was approved by the medical ethics committee of the Leiden University Medical Center. Written informed consent was obtained from all participants.

\section{Serum measurements}

The in vitro quantitative determinations of $25(\mathrm{OH})$ vitamin D3 and intact parathyroid hormone levels in plasma (blood anticoagulated in ethylenediaminetetraacetic acid [EDTA]) were performed with electrochemiluminescence immunoassays on a Cobas e411 analyzer from Roche Diagnostics. Creatinine levels, which we used as a crude measure of kidney function, were measured by the kinetic alkaline picrate method, implemented on an Abbott ci8200 according to the manufacturer's manual.

\section{Other variables}

Height and weight were self-reported. Data about habitual vitamin D intake and vitamin D and multivitamin supplement use (use or no use) were obtained via a validated food frequency questionnaire. ${ }^{12}$ Information about disease history was obtained from the participants' general practitioners, and medication use was obtained from the participants' pharmacies. Information on sun exposure and tanning bed use was obtained by a separate questionnaire in a subpopulation.

\section{Genotyping}

We determined the genotypes of offspring and controls at 3 single nucleotide polymorphisms (SNPs): rs2282679 (GC, group specific components, vitamin D binding protein), rs3829251 (NADSYN1, nicotinamide adenine dinucleotide synthetase 1) and rs2060793 (CYP2R1, cyto chrome P450, family 2 , subfamily R, polypeptide 1). These SNPs have been shown in genome-wide association studies to be associated with vitamin D levels. ${ }^{11}$ We obtained genome-wide SNP data for the offspring and controls by use of Illumina Infinium HD Human660W-Quad BeadChips and Illumina OmniExpress BeadChips. ${ }^{13}$

\section{Statistical analyses}

The levels of $25(\mathrm{OH})$ vitamin D were not normally distributed; thus, we log transformed the data. We categorized the data by month during which blood was drawn. Tanning bed use was categorized into never, $1-5$ times per year, and 6-10 times per year.

We compared data for the offspring and controls using linear regression models. Because serum vitamin $\mathrm{D}$ levels are influenced by age, sex, body mass index (BMI), month of the year (as a measure of the available sun), supplemental intake (vitamin D and multivitamin use) and kidney function (measured by serum creatinine level), we considered these factors to be possible confounding factors, and we included them as covariates in the multivariate linear regression model.

We performed 3 sensitivity analyses. First, we excluded participants who used supplements. Second, we analyzed the data from a random subpopulation (279 offspring and 275 controls) of participants for whom we had information about sun exposure and tanning bed use; we adjusted for these variables in this analysis. Third, we restricted the analysis to participants included in the study as a couple to further minimize the possible effect of environmental differences.

Using data for the entire study population, we repeated the analyses separately for each of the included SNPs. We also analyzed all 3 SNPs together with the potential confounding factors to test whether a difference in vitamin $\mathrm{D}$ level was driven by one of these genotypes.

In all analyses, we corrected for familial relationships among offspring, using residual weight. We considered $p$ values below 0.05 to be statistically significant.

\section{Results}

Data on serum vitamin D levels were available for 2344 participants in the Leiden Longevity Study (1620 offspring and 724 controls). However, data on genetics, self-reported weight and height, and data from the food frequency questionnaire were missing for 582 (35.9\%) offspring and $263(36.3 \%)$ controls, leaving a total of 1038 offspring (from 380 families) and 461 controls for the analyses.

The characteristics of the study population are shown in Table 1 . The offspring were slightly older than the controls, but the groups were similar in the percentage of women and BMI. Intake of vitamin D via food was similar in offspring and controls. The prevalence of type 2 diabetes and hypertension, as well as use of the corresponding medications, were lower in the offspring group than in the control group. 


\section{Vitamin D levels}

The level of vitamin D was inversely correlated with that of parathyroid hormone $(p<0.001)$ and was higher in participants with high sun exposure than in those with low sun exposure $(72.5 \mathrm{nmol} / \mathrm{L}$ v. $62.9 \mathrm{nmol} / \mathrm{L} ; p<0.001)$. Participants who used a tanning bed had higher levels of vitamin D (1-5 times per year: $76.2 \mathrm{nmol} / \mathrm{L}$; 6-10 times per year: $82.1 \mathrm{nmol} / \mathrm{L})$ than those who never used a tanning bed $(68.8 \mathrm{nmol} / \mathrm{L} ; p<0.001)$.

Using a model adjusted for age and sex, we found that offspring had lower levels of vitamin D than controls $(64.3 \mathrm{v} .68 .5 \mathrm{nmol} / \mathrm{L} ; p=0.002)$ (Table 2). These results did not change when we included the other possible confounding factors. The statistically significant difference between offspring and controls persisted when we restricted the analyses to participants who did not use supplements (vitamin D or multivitamin), and when we also adjusted for sun exposure and tanning bed use in a random subpopulation. The results were also consistent in our matched analysis (participants who also had a partner included in the study).

Vitamin D levels were not associated with disease history (e.g., type 2 diabetes, hypertension and myocardial infarction) (Appendix 1, available at www.cmaj.ca/lookup/suppl/doi:10 .1503/cmaj.120233/-/DC1). The difference in vitamin D levels between groups was also observed among participants who were excluded because of missing values (offspring 64.6 $\mathrm{nmol} / \mathrm{L}$ v. controls $68.0 \mathrm{nmol} / \mathrm{L} ; p=0.04)$.

We found no difference in the serum levels of parathyroid hormone between offspring and controls $(39.5$ and $39.4 \mathrm{pg} / \mathrm{mL}$, respectively; $p=$ $0.98)$. In the matched analysis, offspring had lower serum parathyroid hormone levels (37.4 $\mathrm{pg} / \mathrm{mL})$ than controls $(39.1 \mathrm{pg} / \mathrm{mL} ; p=0.049)$.

\section{Genetic variation associated with $25(\mathrm{OH})$ vitamin D levels}

Vitamin D levels by genotype at SNPs in the CYP2R1, GC and NADSYN1 genes for offspring and controls are shown in Table 3 and Appendix 1 (available at www.cmaj.ca/lookup/suppl/doi:10 .1503/cmaj.120233/-/DC1). The common genetic variants of the $C Y P 2 R 1$ and $G C$ genes were significantly associated with serum vitamin D levels in offspring and controls. The difference in vitamin D levels between the offspring and controls persisted when we stratified the analyses by genotype for the 3 SNPs, except for carriers of the homozygous variant genotype for the CYP2R1 and NADSYN1 genes (Table 3).

Common genetic variation in the CYP2R1 gene, which was associated with higher levels of

\begin{tabular}{|c|c|c|c|}
\hline \multirow[b]{2}{*}{ Characteristic } & \multicolumn{2}{|c|}{ No. $(\%)$ or mean \pm SD } & \multirow[b]{2}{*}{$p$ value } \\
\hline & $\begin{array}{c}\text { Offspring } \\
n=1038\end{array}$ & $\begin{array}{l}\text { Controls } \\
n=461\end{array}$ & \\
\hline Age, yr & $59.5 \pm 6.3$ & $58.9 \pm 7.0$ & 0.09 \\
\hline Female & $574(55.4)$ & $257(55.7)$ & 0.9 \\
\hline Body mass index & $25.2 \pm 3.5$ & $25.4 \pm 3.5$ & 0.3 \\
\hline \multicolumn{4}{|l|}{ Vitamin D intake } \\
\hline Via habitual food intake, $\mu \mathrm{g} / \mathrm{d}$ & $3.92 \pm 1.9$ & $3.87 \pm 1.7$ & 0.7 \\
\hline Multivitamin supplements & $298(28.7)$ & $120(26.0)$ & 0.3 \\
\hline Vitamin D supplements & $35 \quad(3.4)$ & $16(3.5)$ & 0.9 \\
\hline Creatinine, $\mathrm{mmol} / \mathrm{L}$ & $80.7 \pm 12.0$ & $82.0 \pm 12.8$ & 0.09 \\
\hline \multicolumn{4}{|l|}{ Disease history } \\
\hline Diabetes mellitus & $28(2.7)$ & $29 \quad(6.3)$ & 0.001 \\
\hline Hypertension & $192(18.5)$ & $110(23.9)$ & 0.02 \\
\hline Myocardial infarction & $16(1.5)$ & $11 \quad(2.4)$ & 0.3 \\
\hline Stroke & $17(1.7)$ & $8 \quad(1.7)$ & 0.9 \\
\hline Malignant disease & $77(7.4)$ & $30 \quad(6.5)$ & 0.4 \\
\hline \multicolumn{4}{|l|}{ Medication use } \\
\hline Diabetes medication & $10(1.2)$ & $14 \quad(3.7)$ & 0.004 \\
\hline Antihypertensive drugs & $127(15.0)$ & $82(21.4)$ & 0.006 \\
\hline Lipid lowering agents & $63(7.5)$ & $37 \quad(8.7)$ & 0.2 \\
\hline
\end{tabular}


vitamin $\mathrm{D}$, was significantly underrepresented ( $p=$ 0.04) among offspring compared with controls (Table 4). The allele frequencies of the common genetic variants were in Hardy-Weinberg equilibrium. The difference in serum levels of vitamin D between the offspring and controls persisted when the 3 genotypes were included as covariates in the statistical model (offspring $61.4 \mathrm{nmol} / \mathrm{mL}$; controls $63.9 \mathrm{nmol} / \mathrm{L} ; p=0.001)$.

\section{Interpretation}

We found that the offspring of nonagenarians who had at least 1 nonagenarian sibling had lower levels of vitamin D than controls, independent of possible confounding factors and SNPs associated with vitamin D levels. We also found that the offspring had a lower frequency of common genetic variants in the CYP2R1 gene; a common genetic variant of this gene predisposes people to high vitamin D levels. These findings support an association between low vitamin D levels and familial longevity.

Previous research has shown that vitamin D has various functions, including bone mineralization, differentiation of immune cells, and inhibition of proliferation and angiogenesis in cancer. ${ }^{2}$ Cross-sectional and longitudinal studies have linked low serum levels of vitamin D to a higher risk of death, cardiovascular disease and cognitive decline. Because of limitations in the design of these studies, it was not possible to infer a causal relation between vitamin $\mathrm{D}$ and outcome. In the case of mortality, low serum vitamin D levels might be a marker of frailty, because ill patients are expected to spend less time outdoors and may have inadequate nutrition. A similar phenomenon might be involved in the proposed relation between low vitamin D and the onset of cardiovascular disease, in which, for example, BMI and low physical activity (which influences vitamin D levels, via lower exposure to sun light) might be residual confounding factors. ${ }^{4,14} \mathrm{~A}$ doubtful causal association between vitamin $\mathrm{D}$ and health outcomes is supported by clinical trials showing a lack of reduction in cardiovascular disease and mortality after vitamin D supplementation. ${ }^{8}$

In our study population, $25(\mathrm{OH})$ vitamin $\mathrm{D}$ levels were not associated with disease history. We found that the offspring of nonagenarian siblings, who had a lower prevalence of cardiovascular diseases and a lower mortality rate compared to controls, ${ }^{9,10}$ had lower levels of vitamin D. The difference in vitamin D levels between offspring and their partners was not explained by any of the potential confounding factors that we investigated. Our results might indicate that low

Table 2: Vitamin D and parathyroid hormone levels in offspring and controls

\begin{tabular}{|c|c|c|c|}
\hline \multirow[b]{2}{*}{ Variable } & \multicolumn{2}{|c|}{ Mean $(95 \% \mathrm{Cl})$} & \multirow[b]{2}{*}{$p$ value } \\
\hline & $\begin{array}{c}\text { Offspring } \\
n=1038\end{array}$ & $\begin{array}{l}\text { Controls } \\
n=461\end{array}$ & \\
\hline \multicolumn{4}{|l|}{$25(\mathrm{OH})$ vitamin $\mathrm{D}, * \mathrm{nmol} / \mathrm{L}$} \\
\hline Model 1† & $64.3(63.1-65.4)$ & $68.5(66.0-71.1)$ & 0.002 \\
\hline Model 2‡ & $64.3(63.1-65.4)$ & $68.4(66.0-71.0)$ & 0.002 \\
\hline \multicolumn{4}{|l|}{ Sensitivity analyses } \\
\hline Supplement users excluded§ & $64.3(63.1-65.4)$ & $68.4(66.0-1.0)$ & 0.002 \\
\hline Matched analysis & $64.5(61.4-69.5)$ & $70.0(65.6-74.7)$ & 0.001 \\
\hline Sun exposure adjusted** & $67.7(62.7-73.1)$ & $72.0(66.4-78.2)$ & 0.02 \\
\hline \multicolumn{4}{|l|}{ Parathyroid hormone,t+ pg/mL } \\
\hline Model 1† & $39.2(38.5-39.9)$ & $39.6(38.1-41.0)$ & 0.7 \\
\hline Model $2 \ddagger$ & $39.3(38.6-40.0)$ & $39.3(37.8-40.7)$ & 0.9 \\
\hline \multicolumn{4}{|l|}{ Sensitivity analyses } \\
\hline Supplement users excluded§ & $39.3(38.6-40.0)$ & $39.3(37.8-40.7)$ & 0.9 \\
\hline Matched analysis & $37.4(35.0-39.9)$ & $39.1(36.5-41.6)$ & 0.049 \\
\hline \multicolumn{4}{|c|}{$\begin{array}{l}\text { Note: } \mathrm{Cl}=\text { confidence interval. } \\
\text { *Vitamin D presented as geometric means with } 95 \% \mathrm{Cl} \text {. } \\
\text { tModel 1: adjusted for sex and age. } \\
\text { fModel 2: model } 1 \text { plus adjustment for body mass index, month of the year blood was drawn, habitual vitamin D intake via } \\
\text { food, use of multivitamin supplements, use of vitamin D supplements, and creatinine level. } \\
\text { §Used model } 2 \text { for analysis; included } 727 \text { offspring and } 332 \text { controls who did not use multivitamin and/or vitamin D } \\
\text { supplements. } \\
\text { १Used model } 2 \text { for analysis; included } 430 \text { offspring and } 430 \text { controls, who were partners. } \\
\star * \text { Used model } 2 \text { for analysis, with additional adjustment for tanning bed use and sun exposure; included } 279 \text { offspring and } 275 \\
\text { controls. } \\
\text { ††Parathyroid hormone levels presented as means with } 95 \% \mathrm{Cl} \text {. }\end{array}$} \\
\hline
\end{tabular}


levels of vitamin D are associated with an increased propensity to reach a very old age.

Vitamin D is produced in the skin in response to ultraviolet $\mathrm{B}$ rays and can also be obtained from food and supplements. In the liver, vitamin D is converted to $25(\mathrm{OH})$ vitamin $\mathrm{D}$, which is later converted in the kidneys to the active hormone that regulates calcium metabolism (1,25 dihydroxyvitamin D $\left[1,25(\mathrm{OH})_{2}\right.$ vitamin $\left.\left.\mathrm{D}\right]\right)$. Vitamin $\mathrm{D}$ status is routinely assessed by the measurement of the serum concentration of $25(\mathrm{OH})$ vitamin $\mathrm{D}$, which is the most stable and abundant metabolite of vitamin D in circulation; this metabolite reflects both vitamin $\mathrm{D}$ intake and endogenous production. Because levels of the active hormone $1,25(\mathrm{OH})_{2}$ vitamin $\mathrm{D}$ do not correlate well with overall vitamin D status, levels of this metabolite are not considered clinically useful. ${ }^{1}$

The synthesis of $1,25(\mathrm{OH})_{2}$ vitamin $\mathrm{D}$ is tightly regulated and is stimulated by serum parathyroid hormone and by low levels of calcium and phosphorus. We do not know whether the lower levels of $25(\mathrm{OH})$ vitamin $\mathrm{D}$ observed in the offspring will also result in lower levels of the active hormone $1,25(\mathrm{OH})_{2}$ vitamin $\mathrm{D}$. We found that serum parathyroid hormone levels were lower in offspring in the analyses restricted to only couples, but not in the other analyses.

Genetically determined differences may exist in vitamin $\mathrm{D}$ metabolism. Indeed, the $C Y P 2 R 1$ gene plays a role in the conversion of vitamin $D$ to $25(\mathrm{OH})$ vitamin $\mathrm{D}$. However, although the allele frequency of a common genetic variant in this gene was underrepresented in the offspring, the difference in serum vitamin $\mathrm{D}$ levels between offspring and controls persisted when we controlled for this genetic variant.

Literature on other potential mechanisms explaining our findings is scarce. We speculate that offspring might have a higher expression of the

Table 3: $25(\mathrm{OH})$ Vitamin D levels in offspring and controls, by genotype

\begin{tabular}{|c|c|c|c|}
\hline \multirow[b]{2}{*}{ SNP, locus } & \multicolumn{2}{|c|}{$25(\mathrm{OH})$ Vitamin $\mathrm{D}(\mathrm{nmol} / \mathrm{L}) ;$ mean $(95 \% \mathrm{Cl})$} & \multirow[b]{2}{*}{$p$ value* } \\
\hline & Offspring & Controls & \\
\hline rs2060793, CYP2R1 & & & $<0.001 \dagger$ \\
\hline Wildtype/wildtype & $61.8(59.9-63.8)$ & $68.7(65.7-71.8)$ & $<0.001$ \\
\hline Wildtype/variant & $64.7(62.7-66.6)$ & $68.3(65.7-71.0)$ & 0.03 \\
\hline Variant/variant & $69.4(65.8-73.3)$ & $72.9(68.4-77.6)$ & 0.2 \\
\hline rs2282679, GC & & & $<0.001 \dagger$ \\
\hline Wildtype/wildtype & $67.2(65.2-69.0)$ & $72.8(70.2-75.6)$ & 0.001 \\
\hline Wildtype/variant & $62.6(60.6-64.7)$ & $66.1(63.4-68.9)$ & 0.05 \\
\hline Variant/variant & $53.1(50.1-56.1)$ & $60.3(55.9-65.0)$ & 0.04 \\
\hline rs3829251, NADSYN1 & & & $0.8 \dagger$ \\
\hline Wildtype/wildtype & $63.8(62.2-65.2)$ & $68.6(66.4-70.7)$ & 0.001 \\
\hline Wildtype/variant & $64.8(62.1-67.6)$ & $70.1(66.3-74.2)$ & 0.05 \\
\hline Variant/variant & $62.4(55.4-70.2)$ & $68.3(59.9-78.5)$ & 0.3 \\
\hline \multicolumn{4}{|c|}{$\begin{array}{l}\text { Note: } \mathrm{Cl}=\text { confidence interval, } \mathrm{SNP}=\text { single nucleotide polymorphism. } \\
\text { * Analyses were adjusted for age, sex, body mass index, month of the year that blood was drawn (except rs } 3829251 \text {, because } \\
\text { the number of participants with the variant/variant genotype was too low), vitamin } \mathrm{D} \text { use, multivitamin supplement use, and } \\
\text { habitual vitamin } \mathrm{D} \text { intake per day. } \\
\text { tPooled } p \text { value (offspring and controls) of the association between the genetic variant and vitamin } \mathrm{D} \text { level. }\end{array}$} \\
\hline
\end{tabular}

Table 4: Comparison of genetic variation associated with vitamin D between offspring and controls

\begin{tabular}{|c|c|c|c|c|c|c|}
\hline \multirow{2}{*}{$\begin{array}{l}\text { Single } \\
\text { nucleotide } \\
\text { polymorphism }\end{array}$} & \multirow[b]{2}{*}{$\begin{array}{l}\text { Gene or } \\
\text { locus }\end{array}$} & \multirow[b]{2}{*}{ Location } & \multirow[b]{2}{*}{$\begin{array}{l}\text { Minor } \\
\text { allele }\end{array}$} & \multicolumn{2}{|c|}{ Minor allele frequency } & \multirow[b]{2}{*}{$p$ value } \\
\hline & & & & $\begin{array}{c}\text { Offspring } \\
n=1038\end{array}$ & $\begin{array}{c}\text { Controls } \\
n=461\end{array}$ & \\
\hline rs2282679 & GC & $4 q 13.3$ & C & 0.263 & 0.270 & 0.6 \\
\hline rs3829251 & NADSYN1 & $11 q 13.4$ & A & 0.154 & 0.163 & 0.6 \\
\hline rs2060793 & CYP2R1 & $11 \mathrm{p} 15.2$ & A & 0.371 & 0.418 & 0.04 \\
\hline
\end{tabular}

Analyses were adjusted for age, sex and familial relationship.

Note: CYP2R1 = cytochrome P450, family 2, subfamily R, polypeptide 1; GC = group specific component (vitamin D binding protein); NADSYN1 = nicotinamide adenine dinucleotide synthetase 1. 
klotho protein, which is hypothesized to be an "aging suppressor" protein. Lifespan was significantly longer in mice overexpressing this protein. ${ }^{15}$ In contrast, mice lacking the klotho gene aged faster and had higher levels of vitamin D than control mice. Elimination of vitamin D from food slowed the aging process, suggesting that vitamin $\mathrm{D}$ is directly linked to aging. ${ }^{16,17} \mathrm{~A}$ study involving humans reported that high levels of serum klotho protein were associated with a lower rate of mortality, ${ }^{18}$ lower risk of cardiovascular disease,,$^{19}$ and stronger grip strength in older adults. ${ }^{20}$ Further research should elucidate whether the expression level of klotho explains the findings presented in this study.

\section{Limitations}

A limitation of this study is that data on tanning bed use and sun exposure were available only for a small subpopulation of participants. However, the subpopulation was random, and vitamin D levels were similar to those in the whole study population. A second limitation is that many participants $(36 \%)$ were excluded from our analyses because information about possible confounding factors was missing; multiple imputations analysis was not possible for this group. However, the difference in vitamin D levels was also present among the excluded participants, suggesting that the participants included in our study are representative of the total study group.

\section{Conclusion}

We found that familial longevity was associated with lower levels of vitamin D and a lower frequency of allelic variation in the CYP2RI gene, which was associated with higher levels of vitamin D. Future research should focus on elucidating the mechanisms that explain the lower $25(\mathrm{OH})$ vitamin D levels in familial longevity and other genetic variants associated with vitamin D metabolism, such as the vitamin D receptor. ${ }^{18-23}$

\section{References}

1. Holick MF. Vitamin D deficiency. N Engl J Med 2007;357:266-81

2. Deeb KK, Trump DL, Johnson CS. Vitamin D signalling pathways in cancer: potential for anticancer therapeutics. Nat Rev Cancer 2007;7:684-700.

3. Mathieu C, Gysemans C, Giulietti A, et al. Vitamin D and diabetes. Diabetologia 2005;48:1247-57.

4. Lee JH, Gadi R, Spertus JA, et al. Prevalence of vitamin D deficiency in patients with acute myocardial infarction. Am J Cardiol 2011;107:1636-8

5. Pilz S, Dobnig H, Nijpels G, et al. Vitamin D and mortality in older men and women. Clin Endocrinol (Oxf) 2009;71:666-72.

6. Pilz S, Tomaschitz A, März W, et al. Vitamin D, cardiovascular disease and mortality. Clin Endocrinol (Oxf). 2011;75:575-84.

7. Thacher TD, Clarke BL. Vitamin D insufficiency. Mayo Clin Proc 2011;86:50-60.

8. Elamin MB, Abu Elnour NO, Elamin KB, et al. Vitamin D and cardiovascular outcomes: a systematic review and meta-analysis. J Clin Endocrinol Metab 2011;96:1931-42.

9. Westendorp RG, van Heemst D, Rozing MP, et al. Nonagenarian siblings and their offspring display lower risk of mortality and morbidity than sporadic nonagenarians: the Leiden Longevity Study. J Am Geriatr Soc 2009;57:1634-7.

10. Schoenmaker M, de Craen AJ, de Meijer PH, et al. Evidence of genetic enrichment for exceptional survival using a family approach: the Leiden Longevity Study. Eur J Hum Genet 2006; 14:79-84

11. Ahn J, Yu K, Stolzenberg-Solomon R, et al. Genome-wide association study of circulating vitamin D levels. Hum Mol Genet 2010;19:2739-45.

12. Verkleij-Hagoort AC, de Vries JH, Stegers MP, et al. Validation of the assessment of folate and vitamin B12 intake in women of reproductive age: the method of triads. Eur J Clin Nutr 2007;61:610-5.

13. Deelen J, Beekman M, Uh HW, et al. Genome-wide association study identifies a single major locus contributing to survival into old age; the APOE locus revisited. Aging Cell 2011;10:686-98.

14. Nadir MA, Szwejkowski BR, Witham MD. Vitamin D and cardiovascular prevention. Cardiovasc Ther 2010;28:e5-12.

15. Kurosu H, Yamamoto M, Clark JD, et al. Suppression of aging in mice by the hormone klotho. Science 2005;309:1829-33.

16. Medici D, Razzaque MS, Deluca S, et al. FGF-23-Klotho signaling stimulates proliferation and prevents vitamin D-induced apoptosis. J Cell Biol 2008;182:459-65.

17. Tsujikawa H, Kurotaki Y, Fujimori T, et al. Klotho, a gene related to a syndrome resembling human premature aging, functions in a negative regulatory circuit of vitamin D endocrine system. Mol Endocrinol 2003;17:2393-403.

18. Semba RD, Cappola AR, Sun K, et al. Plasma klotho and mortality risk in older community-dwelling adults. J Gerontol A Biol Sci Med Sci 2011;66:794-800.

19. Semba RD, Cappola AR, Sun K, et al. Plasma klotho and cardiovascular disease in adults. J Am Geriatr Soc 2011:59:1596-601.

20. Semba RD, Cappola AR, Sun K, et al. Relationship of low plasma klotho with poor grip strength in older community-dwelling adults: the InCHIANTI study. Eur J Appl Physiol 2011;112:1215-20.

21. Cyganek K, Mirkiewicz-Sieradzka B, Malecki MT, et al. Clinical risk factors and the role of $V D R$ gene polymorphisms in diabetic retinopathy in Polish type 2 diabetes patients. Acta Diabetol 2006;43:114-9.

22. Tworowska-Bardzinska U, Lwow F, Kubicka E, et al. The vitamin $\mathrm{D}$ receptor gene $B s m \mathrm{I}$ polymorphism is not associated with anthropometric and biochemical parameters describing metabolic syndrome in postmenopausal women. Gynecol Eendocrinol 2008; 24:514-8.

23. Zmuda JM, Cauley JA, Ferrell RE. Molecular epidemiology of vitamin D receptor gene variants. Epidemiol Rev 2000;22:203-17.

Affiliations: From the Department of Gerontology and Geriatrics (Noordam, de Craen, Pedram, Maier, Mooijaart, Westendorp, van Heemst), Leiden University Medical Center, Leiden; the Laboratory of Clinical Chemistry, Hematology and Immunology (van Pelt), Medical Center Alkmaar, Alkmaar; the Division of Human Nutrition (Feskens, Streppel), Wageningen University, Wageningen; the Section of Molecular Epidemiology (Slagboom, Beekman), Department of Medical Statistics and Bioinformatics, Leiden University Medical Center, Leiden; and the Netherlands Consortium for Healthy Ageing (de Craen, Maier, Mooijaart, Slagboom, Westendorp, Beekman, van Heemst), the Netherlands.

Contributors: Anton De Craen, Diana van Heemst, Simon Mooijaart, Andrea Maier, Rudi Westendorp, and Eline Slagboom designed the Leiden Longevity Study and recruited the participants. Raymond Noordam, Anton de Craen, Pardis Pedram and Diana van Heemst performed the data analyses, interpreted the initial analyses and drafted the first version of the manuscript. Marian Beekman, Eline Slagboom, Johannes van Pelt, Martinette Streppel and Edith Feskens acquired the data. All authors critically commented on the initial versions of the manuscript and approved the final version submitted for publication.

Funding: This study was supported by the Innovation Oriented Research Program on Genomics (SenterNovem; IGE1014 and IGE5007), the Centre for Medical Systems Biology and the Netherlands Genomics Initiative/Netherlands Organisation for Scientific Research (05040202 Netherlands Consortium for Healthy Ageing).

Acknowledgements: The authors thank the general practitioners and pharmacists who participated in the Leiden Longevity Study, as well as Meriam H. van der Star and Ellen H. Bemer-Oorschot for their valuable contributions. 